\title{
THE FROST-RESISTANCE OF CONCRETE
}

\section{James R. Clifton}

\author{
U.S. DEPARTMENT OF COMMERCE \\ National Instltute of Standards \\ and Technology \\ Center for Bullding Technology \\ Galthersburg, MD 20899
}

U.S. DEPARTMENT OF COMMERCE Robert A. Mosbacher, Secretary Loe Mercer, Deputy Under Secretary for Tochnology

NATIONAL INSTITUTE OF STANDARDS AND TECHNOLOGY

Raymond G. Kammer, Acting Director

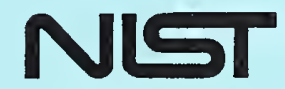





\section{THE FROST-RESISTANCE OF CONCRETE}

\section{James R. Clifton}

U.S. DEPARTMENT OF COMMERCE National Institute of Standards and Technology Center for Bullding Technology Galthersburg, MD 20899

January 1990

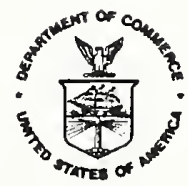

U.S. DEPARTMENT OF COMMERCE Robert A. Mosbacher, Secretary

Lee Mercer, Deputy Under Secretary for Technology

NATIONAL INSTITUTE OF STANDARDS AND TECHNOLOGY

Raymond G. Kammer, Acting Director 

Freezing of water in the pores of concrete is one of the major degradation processes of concrete. It results in cracking and reduced service life. Concrete exposed to frost conditions may rapidly degrade or be durable for decades. This report reviews the major factors affecting the frost resistance of concrete and test methods for evaluating the service life of concrete. Mathematical models which describe the mechanisms of frost damage and methodologies for predicting the durability of concrete exposed to frost conditions are reviewed to determine their relevance to service life predictions.

KEYWORDS: Aggregate; concrete; durability; entrained-air; freezing; frost; models; service life; testing. 
1. Introduction $\ldots \ldots \ldots \ldots \ldots \ldots \ldots \ldots \ldots \ldots \ldots \ldots \ldots \ldots$

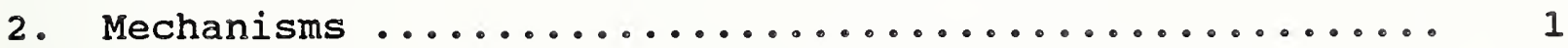

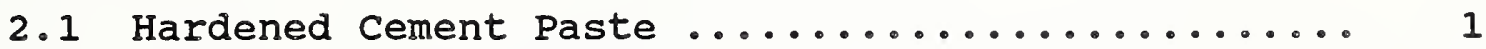

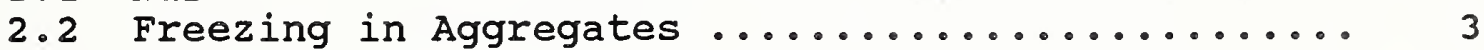

3. Resistance to Freezing ..................... 4

3.1 Exposure Conditions .................. 4

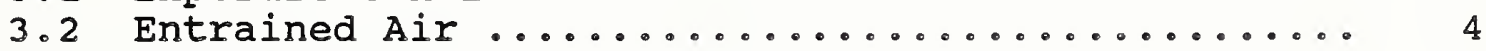

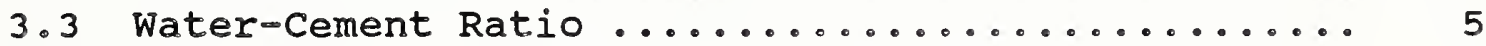

3.4 Selection of Materials .................... 5

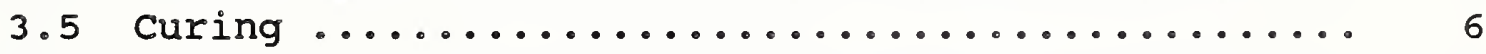

4. Test Methods to Evaluate Frost Resistance of Concrete - 6

4.1 Rapid Freezing and Thawing Test ............. 6

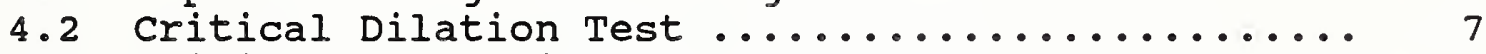

4.3 Critical Saturation Test .................. 7

5. Mathematical Models of Frost Resistance of Concrete ... 8

5.1 Critical Degree of Saturation Model .......... 8

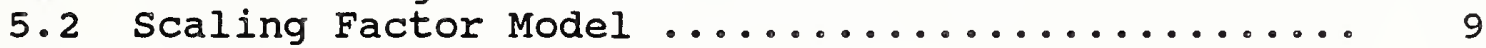

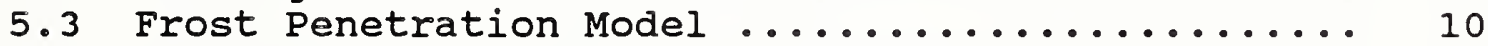

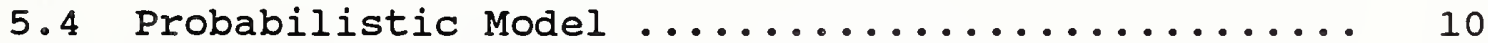

5.5 Freezing and Thawing Process Model ............ 11

5.6 Remarks on Models for Service Life Predictions .. 11

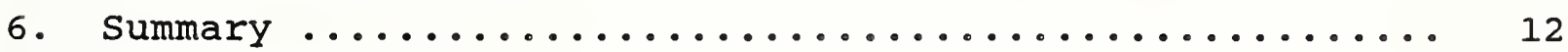

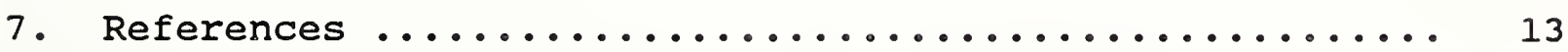

List of Tables

Table 1. Recommended Air Contents for Frost-Resistance

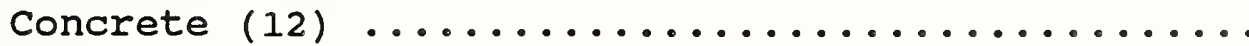





\section{INTRODUCTION}

Frost damage (also called freezing and thawing damage) can be a serious problem for concrete resulting in its cracking and reduced service life. The recent National Materials Advisory Board report "Concrete Durability: A Multibillion-Dollar opportunity" identified freezing and thawing as one of the most important durability problems for concrete (1). Frost damage occurs when wet concrete is exposed to cycles of freezing and thawing. Concrete does not need to be fully saturated with water for damage to occur as the critical level of saturation is around 85 percent for most concretes (2). Critical saturation is the level of saturation of concrete above which frost damage can occur (3). Horizontal concrete surfaces on which water can pond (e.g., pavements, bridge decks, flat roofs, and sills) and other concrete structures exposed to continuously wet environments (e.g., bridge piers and offshore structures) are especially vulnerable to frost damage.

In most cases, concrete can be made to resist frost damage by proper mix design, including incorporation of the proper amount of entrained air, selection of a frost-resistant aggregate, and proper placement, consolidation, and curing. However, in unusual conditions, even air-entrained concrete may be damaged by cyclic freezing, especially if it is kept in a condition of near saturation while exposed to freezing temperatures.

This report reviews the factors affecting the service life of concrete exposed to frost conditions, including degradation mechanisms, test methods for evaluating the frost resistance of concrete, and models for predicting service life. The purpose of the review is to contribute to the formation of an improved conceptual basis for modeling the service life of concrete.

\section{MECHANISMS}

Both the hardened cement paste and the aggregates in concrete can undergo frost damage. The hardened cement paste can be designed to be more resistant to frost damage, while little can be done to improve the resistance of an aggregate except to select another aggregate. Therefore, the mechanisms in the hardened cement paste will be discussed in more detail than those for aggregates.

\subsection{Hardened Cement Paste}

Several mechanisms of the freezing process in hardened cement paste have been proposed and the most widely accepted mechanisms are discussed.

When water freezes in the pore system of hardened cement paste, expansive stresses are developed which, if they exceed the tensile strength of the paste, can cause severe cracking. An early 
explanation developed by Powers $(4,5)$ was that hydraulic pressures are developed in the pores because water expands in volume by $9 \%$ when converted to ice. The expansion causes excess water to move from the site of freezing to adjacent pores or other voids. Large hydraulic pressures can be developed by resistance to the movement of water from the site of freezing, particularly if the voids are not close to the sites of freezing or are not large enough to accommodate all the water. cracking occurs if the hydraulic pressures exceed the tensile strength of the hardened cement paste. This hypothesis predicts that the magnitude of the developed pressure will depend on the rate of freezing, extent of saturation and permeability of the paste, and the distance from the freezing site to the nearest air-filled pore. Thus, entrained air should improve the frost resistance of the paste by decreasing the average distance of the flow-path. The hydraulic pressure mechanism does not account for many of the processes observed when water in a concrete with a predominant amount of small pores freezes. For example, Powers and Helmuth $(6,7)$ later observed that during freezing of cement paste most of the water movement is toward, not away from sites of freezing. Also, the amount of dilation (expansion) during freezing generally decreases with increased rate of cooling, contrary to the hydraulic pressure hypothesis. However, the hydraulic pressure mechanism appears to be active when water in porous concretes, with a large interconnected pore system, freezes (8).

Another explanation developed by Powers (6) and Helmuth (7) is analogous to the mechanism that causes frost heave in soils. In this ice accretion hypothesis, osmotic pressures are developed. Ice crystals formed in the capillary pores are able to attract unfrozen water from other pores because of differences in free energy (or vapor pressure) between ice and unfrozen water, resulting in the movement of water vapor to the site of freezing where it condenses as ice. At first, the free energy of the ice (measured by its vapor pressure) is lower than that of the unfrozen water in the gel pores. Because of the internal desiccation process, the free energy of the ice crystal increases while the free energy of the unfrozen water in the gel pores decreases. The ice crystal continues to grow until the free energies are equal. Sufficient osmotic pressures can develop to cause cracking of the hardened cement paste. According to this hypothesis, when the paste contains entrained air bubbles and the average distance between them is less than a critical size, the unfrozen water preferentially migrates to the air bubbles rather than to the capillaries. By this process the osmotic pressure is reduced to below the tensile strength of the hardened cement paste.

The relative importance of the two mechanisms, involving either hydraulic pressure or osmotic pressure, is not unambiguously known. However, it appears that the osmotic pressure mechanism should be most effective in concretes with small pores, such as concretes with low water-to-cement (w/c) ratios, and it is most likely to 
cause damage if the concrete remains frozen for an extended period (8). Conversely, the hydraulic pressure mechanisms would probably be active in highly porous concrete, and is most likely to cause damage when the rate of freezing is rapid (8).

A more recent hypothesis proposed by Litvan (9) suggests that the water absorbed on the surface or contained in the pores of cement paste which cannot freeze is involved in the damage process. This water supercools and because of the difference in its vapor pressure and that of the bulk ice, it migrates to locations where it can freeze. Partial desiccation of the paste occurs and ice accumulates in cracks and voids, including entrained air bubbles. Failure occurs if the water cannot be redistributed properly to locations where freezing does not result in development of internal stresses sufficient to cause cracking. The water may not be able to redistribute properly because the amount of water is too great (high level of saturation), the available time is too short (rapid cooling), or the path of migration is too long (lack of entrained air bubbles). In such cases, the water is unable to form ice crystals and instead forms a semi-amorphous solid which results in internal stresses that may exceed the tensile strength of the hardened cement paste.

Regardless of which proposed mechanism is correct, the resistance of hardened cement paste to frost action is known (3) to depend on the spacing of entrained air bubbles, the amount of water in the pores of the paste, the salt content of the pore water, the permeability of the paste, the freezing rate, and the strength of the paste.

\subsection{Freezing in Aggregates.}

Most rocks have pore sizes much larger than those in cement paste and they expel water during freezing (4). Some aggregates have an appreciable volume of fine pores and if they contain large amounts of absorbed water, cracking can occur through ice formation (10). D-cracking in pavements is attributed to be the freezing of water in porous aggregates $(3,12)$. The size of an aggregate can control its resistance to frost damage, with frost resistance increasing as size decreases. A critical size exists below which aggregates can be exposed to freezing temperatures while saturated with water without being damaged (11). Some aggregates (e.g., marble, basalt, granite, quartzite) have such low capacities for freezable water that they are resistant to damage regardless of their size (12). A more comprehensive discussion of the effects of aggregates on the frost resistance of concrete is provided by cordon (3). 
The resistance of concrete to freezing damage is controlled by several factors including exposure conditions, mixture design of the concrete (e.g., amount and distribution of entrained air, w/c ratio, amount of cement), selection of materials, consolidation and curing of the concrete. The degree of freezing damage to a concrete structure also depends on its size and its geometry.

\subsection{Exposure Conditions}

The exposure conditions dictate if freezing and thawing damage to concrete is likely to occur. Concrete must contain liquid water and be exposed to freezing temperatures for any freeze-thaw damage to take place. As indicated in Table 1, the amount of air which needs to be entrained depends on the severity of the exposure. According to the ACI Guide to Durable concrete (12), a severe exposure is defined as a cold climate where the concrete may be in almost continuous contact with water prior to freezing, or where deicing salts are used. If the exposure to water prior to freezing only occasionally occurs, then the exposure is classified as moderate. Even air-entrained concrete may suffer frost damage if it is in a state of nearly complete saturation and the when exposed to freezing temperatures (8). Fagerlund has postulated (8) that entrained air concrete may be susceptible to frost damage if a certain amount of the entrained air bubbles are filled with water. This could occur if the concrete is exposed to flowing or ponding water for a lengthy period of time.

\subsection{Entrained Air.}

An important factor controlling the performance of concrete subjected to freezing conditions is the entrained air bubble system. Too little entrained air will not protect hardened cement paste against frost damage, while too much air may result in a significant reduction in strength. Recommended air contents are given in Table 1 for severe and moderate exposures for normal strength concretes, e.g., concretes with compressive strengths below $55 \mathrm{MPa}$ (12). The values may be slightly lowered if the performance of the concrete in a specific environment is known. If the path of migration (i.e., distance from a water-filled capillary pore to the nearest entrained air bubble) for water is too long, frost damage will occur even if entrained air is present. The hydraulic or osmotic pressure will increase with the distance between air bubbles. Therefore, the air bubbles should be distributed so that there are no locations of water in the hardened cement paste so far removed from an air bubble that the hydraulic or osmotic pressure can exceed the tensile strength of the paste. The air voids in the hardened cement paste are recommended to have a maximum spacing of $0.4 \mathrm{~mm}$ or a spacing factor of $0.2 \mathrm{~mm}$ (12). 
The spacing factor is defined as the maximum distance from any point in a cement paste from the periphery of an air bubble (13). The need for entraining air in high-strength concretes (compressive strengths greater than $55 \mathrm{MPa}$ ) is a controversial issue $(14,15)$. The resistance to freezing is dependent on the capacity of concrete for freezable water. By reducing the porosity and permeability of concretes through decreasing their w/c ratios, their capacity for freezable water (freezable water is the water that will freeze when the temperature drops to a particular value (16)) should be reduced. Therefore, in principle, it should be possible to produce low $\mathrm{w} / \mathrm{c}$ ratio high-strength concretes that do not need entrained air to resist frost damage. However, some studies have indicated that non-air entrained high-strength concretes do not perform satisfactorily in laboratory tests (14). Philleo (15) suggested that low $\mathrm{w} / \mathrm{C}$ ratio concretes may have no capacity for freezable water if all the available space in the hardened cement paste is filled with hydration products; or if the paste becomes so impermeable that saturation by water will not occur. This reasoning, however, implies that non-air entrained high-strength concretes could undergo frost damage if they were exposed to freezing conditions before being completely cured.

\section{3 water-Cement Ratio.}

In addition to entrained air, the $\mathrm{w} / \mathrm{C}$ ratio must be controlled to obtain concrete resistant to freezing and thawing cycles. The tensile strength of concrete increases with decreasing w/c ratio and, thus, improves its ability to withstand the stresses caused by freezing processes. Also, the paste becomes less permeable which increases the time for critical saturation to be reached. Therefore, the ACI "Guide to Durable concrete" recommends (12) that normal weight concrete exposed to freeze-thaw conditions should have a w/C ratio not to exceed the following:

1) Thin sections and sections with less than $25 \mathrm{~mm}$ of cover over

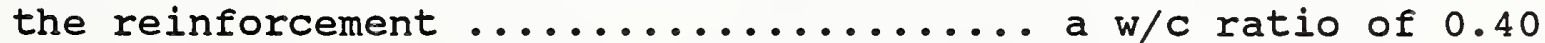

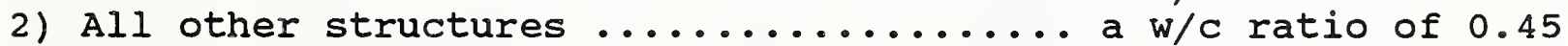

Because of uncertainties about the absorption of water by lightweight aggregates, it is not practical to specify the w/c of concretes containing such aggregates. For such concretes, a 28day compressive strength and a minimum cement content is recommended by the ACI Guide to Durable concrete (12).

\subsection{Selection of Materials.}

Whenever a durable concrete is desired, the constituents, (cement, aggregates, and mineral and chemical admixtures) should meet the requirements of the appropriate ASTM specifications. The different types of portland and blended cements, when used in properly 
proportioned and prepared air-entrained concrete, will provide similar resistance to frost damage. Most fly ashes and natural pozzolans when used as admixtures produce durable concrete provided that the recommended air content and strength can be attained (12). If possible, highly absorptive aggregates should not be used.

\section{5 curing.}

Proper curing can be very important because immature air-entrained concrete can be damaged if it has not developed adequate strength before being exposed to freezing conditions. Also, the amount of freezable water present in the pore structure decreases with hydration. The following recommendations for strength developments are given in the ACI Guide for Durable concrete (12): (i) normal strength air-entrained concrete should be able to resist a few cycles of freezing and thawing when it attains a compressive strength of about $3.45 \mathrm{MPa}$, provided it is not exposed to an external source of moisture; and (ii) concrete should attain a compressive strength of $28 \mathrm{MPa}$ before being subjected to severe freezing and thawing exposure, or if the exposure is moderate, then a compressive strength of $21 \mathrm{MPa}$ should be adequate.

\section{TEST METHODS TO EVALUATE FROST RESISTANCE OF CONCRETE}

\subsection{Rapid Freezing and Thawing Test}

The most widely used laboratory test for evaluating the frost resistance of concrete is ASTM C 666 (17). It involves subjecting concrete, which is initially saturated with water, to rapid cycles of freezing and thawing. In Procedure $A$ of the test, rectangular prisms of concrete are frozen and thawed in water, while in Procedure $B$ the prisms are frozen in air and thawed in water. In a single cycle, the specimens are cooled from 4.4 to $-17.8^{\circ} \mathrm{C}$ and then warmed to $4.4^{\circ} \mathrm{C}$, within a 2 to $5 \mathrm{hr}$ period. The durability of the concrete is determined by measuring the reduction in its dynamic modulus. The test does not realistically simulate inservice conditions because the temperature changes are very rapid and failure in the test appears to result from excessive hydraulic pressure, possibly combined with the rapid temperature change. Under actual exposure condition, the temperature changes are more gradual and in cold areas the concrete may be frozen for many days. Failure of concrete in service, especially if frozen for several weeks, is likely to involve ice accretion. However, the relative performance of concretes and aggregates in the test appear to adequately predict their relative performance in the field, which is of great assistance in selecting durable concrete. Some concretes have been found to only have fair performance in the test but still have adequate in-service frost resistance. If a concrete has a high durability factor after 300 cycles it should be able to 
withstand a severe freezing and thawing environment. At present C 666 is regarded as the "standard test" and is the most widely used test (12).

\subsection{Critical Dilation Test}

ASTM C 671 (18) has been developed to more closely simulate the moisture conditions and freezing rates encountered in field exposures and is less severe than ASTM C 666. In this test, cylindrical specimens are cooled from 1.7 to $-9.4 . \mathrm{C}$ at a rate of $2.8 \mathrm{C} / \mathrm{hr}$ and then warmed back to $1.7 . \mathrm{C}$. The length of a specimen is measured after each cycle. Usually the length change from one cycle to the next is relatively constant until the critical dilation is reached, thereafter the length change is significant (19). The critical dilation, which occurs when dilation begins to increase sharply (by a factor of 2 or more) (18), is taken to indicate failure. The test is more flexible than ASTM C 666 because its testing conditions can be modified to more closely simulate field conditions. Several factors have impeded its use, including that it requires more expensive equipment and usually requires more time to perform than $C$ 666. Also, the results obtained with $C 671$ are sensitive to the moisture content of the concrete prior to testing. However, it has been suggested that $C$ 671 is a more realistic test for high strength concrete than C 666 (15). A similar test exists for evaluating the frost resistance of coarse aggregate, ASTM C 682 (20). It is used to compare the effects of different aggregates on the frost resistance of concrete.

\subsection{Critical Saturation Test}

A RILEM (International Union of Testing and Research Laboratories for Materials and structures) test (21) for determining the critical level of saturation for assessing the frost resistance of concrete has been developed based on the work by Fagerlund $(8,22)$. In this test, absorption tests are carried out to indicate the approximate time required for concrete to reach the critical degree of saturation. The frost resistance of concrete in a structure at a given time is the difference between the critical saturation and the actual level of saturation at that time. One method, the multicycle method, for determining the critical degree of saturation is:

(1) Specimens with various known water contents are sealed in plastic bags and then subjected to six or more cycles of freezing and thawing.

(2) A temperature of $-10 \cdot \mathrm{C}$ is reached 5 to $6 \mathrm{hr}$ after the freezing part of the cycle is initiated, and $-20 . \mathrm{C}$ is reached after 8 to $9 \mathrm{hr}$. 
(3) Then the specimens are warmed to $5 \cdot \mathrm{C}$, and a new cycle is started. After six cycles, the specimens are tested for failure. Specimens which have not failed are allowed to absorb additional water and then are subjected again to freeze-thaw cycles. The process is continued until a sufficient number of specimens have failed to permit a reliable determination of the critical level of saturation.

(4) The degree of saturation at which frost damage is initiated is defined as the critical degree of saturation. Damage is monitored by measuring the dynamic modulus.

The absorption test conditions may be designed to simulate actual field conditions.

The test provides qualitative information on the durability of concrete. Concretes with high frost resistance values are likely to be more durable than those with low frost resistance values (8).

\section{MATHEMATICAL MODELS OF FROST RESISTANCE OF CONCRETE}

Mathematical models which describe the mechanisms of frost damage, or may be used in the prediction of the durability of concrete exposed to frost conditions, are reviewed to determine their relevance to service life predictions.

\section{I Critical Degree of Saturation Model}

A model for predicting the service life of air-entrained concrete exposed to freezing and thawing cycles has been developed by Fagerlund $(8,22)$. It is the basis of the critical saturation Test (see section 4.3). The main aspects of it are outlined in the following. In the model, air bubbles are termed "air voids." The spacing of unfilled air voids is treated as a variable because it changes when water is filling the air void system (air void absorption). Frost damage will not occur until the air void absorption reaches a critical value (i.e., the critical air void absorption) and freezing temperatures are encountered. Methods for obtaining the critical air absorption have been described by Fagerlund based on the air void volume and distribution, and the spacing of unfilled air voids.

The model considers that the complete volume of concrete in a structure rarely fails during one freezing and thawing cycle but occurs progressively, i.e., starting from the outer regions of a volume of concrete, damage spreads inward through many freezing and thawing cycles. The period of service of an element of concrete is the period of time during which the amount of air void absorption in the element is always lower than its critical air void absorption, during periods of freezing temperatures. The 
service life of the structure is the period of time after which the structure can no longer fulfill its purpose because of frost damage. A structure in constant contact with water and exposed to freezing temperatures will have a finite service life because eventually the critical air void absorption will be exceeded. However, a structure that goes through cycled wetting and drying phases could have a finite or infinite life, with regard to frost damage, depending if the level of the critical air void absorption is reached while the concrete is freezing. Therefore, the prediction of the service life of the concrete, with respect to frost damage, can be based on a probabilistic analysis.

The model is intended to give a means for making a reasonable estimate of the service life of concrete. To make a reasonable service life prediction, relationships for the long-term absorption process in the air void system must be known as a function of the properties of the concrete, such as permeability, air void volume, and air void distribution. Several examples of service life predictions made using the model are given by Fagerlund (22) for concrete with non-porous aggregate.

\subsection{Scaling Factor Model}

Vesikari (23) described a model developed for evaluating the service life of concrete exposed to frost and salt scaling action. In this model, a frost resistance index (P) times an environmental factor $\left(k_{\ominus}\right)$ gives the estimated service life $\left(t_{1}\right)$ :

$$
t_{1}=k_{e} \cdot P
$$

$P$ can be obtained from the DBV (Deutsche Beton Verein) freeze-salt test (23). In this test the volume decrease of specimens during 25 cycles of freezing and thawing are determined. Then the number of cycles required to produce a $4 \%$ volume decrease is obtained by extrapolation and the frost resistance index is calculated. The volume decrease is associated with the degradation of the concrete. $P$ can also be obtained from an empirical equation, in which the inputs are a binder factor (K) which depends on the type of cement, the percentage of unfilled pores of concrete submerged in water under normal atmospheric pressure $\left(P_{r}\right)$, and the compressive strength of the concrete $\left(f_{c}\right)$

$$
P=23 \cdot K \cdot\left(P_{r}-5\right) /\left(60-f_{c}\right) .
$$

Values of the environmental factor $(k)$ in equation (1) were based on field investigations in which the correlation between the degree of damage, age of the structure, and the frost resistance index of the concrete were studied. At the present stage of development the model cannot be expected to give more than qualitative predictions. 
Nevertheless, the approach pursued by Vesikari (23) to link laboratory and field investigations in making service life predictions possibly could be applied to other types of concrete degradation.

\subsection{Frost Penetration Model}

A two-dimensional finite element computer model for predicting frost penetration in saturated aggregates and concrete has been developed by olsen (24). Based on differential equations for predicting temperature and moisture content, and equations relating freezing temperatures and water potential, the model predicts temperature, depth of frost penetration, water and ice content of aggregates or concrete, and the pore water pressure. The model was shown to give predicted values of the frozen water content of cement paste as a function of temperature which are in reasonable agreement with experimental data. However, the validity of several assumptions made in developing the model and the sensitivity of the model to these assumptions needs to be determined.

The model can be used to analyze the influence of its parameters on the freezing process. For example, the effect of selecting aggregates with different desorption properties on frost durability can be evaluated. However, the model treats concrete as a continuum and thus does not consider the effect of pore and entrained-air structures on its frost resistance. Also, the model is applicable only to concrete known to be saturated. To be used in predicting the service life of a concrete structure, the model would need to be linked to a model predicting the rate and path of water movement in concrete so that regions of critical saturation which experience freezing temperatures can be predicted.

\subsection{Probabilistic Model}

A probabilistic procedure for predicting service life of concrete subjected to frost damage was developed by Bryant and Mlakar (25). It is based on determining the probability that concrete would be subjected to freezing temperatures while critically saturated. The model was applied to two U.S. Army Corps of Engineers structures.

The probability that a concrete structure would be subjected to freezing temperature was based on analysis of weather data from the nearest weather station. Then the temperature of a specific unit volume of concrete in the structure was estimated by a heattransfer finite element analysis. Moisture migration and the degree of saturation was addressed by modeling convection (permeability). The model was applied to two lock structures, containing non-air entrained concrete which have been in service for some 60 years. Reasonable agreement was considered to be obtained between predicted and measured depth of frost damage for 
concrete near the water line. Because of the inadequacy of models of water movement in porous systems, the model appears to be limited to concrete structures in constant contact with water and for the concrete which is near the water line. The model does not consider the effect of entrained-air on the frost resistance of concrete, Also, the model does not consider the effect of salts on the freezing point depression of water.

\subsection{Freezing and Thawing Process Model}

Bazant, et al., (26) developed a model which involves the formulation of relationships for sorption isotherms for concrete exposed to freezing temperatures, diffusion of water, temperature distribution, and internal stresses in the concrete resulting from the freezing of water. The model essentially reduces the freezing and thawing durability problem to the calculation of stresses and strains. Solution of the model would require finite-element computer analysis. To apply the model, information is needed on the effect of mechanical loading on the freezing and thawing process. In its present stage of development, the model does not relate the amount of damage to the number of frost cycles and, therefore, it does not make service life predictions.

\subsection{Remarks on Models for Service Life Predictions}

Taken together, the above models provide an useful technical basis for making realistic service life predictions of both new and existing concrete structures, which will be or have been, exposed to frost conditions. One approach for predicting the service life of concrete exposed to frost conditions could consist of the following steps:

Step 1. Determine the distribution of critically saturated regions in a concrete structure, considering both the capillary and air bubble structures.

Step 2. Estimate the probability of the structure being exposed to freezing temperatures while some concrete unit volumes are critically saturated.

Step 3. Determine the depth of damage occurring per frost cycle in critically-saturated concrete volumes. Treat the progression of depth of frost damage as a moving front process.

Step 4. Define failure, e.g., 50\% of the thickness of a concrete slab is cracked, and then calculate the time required for failure. 
A major obstacle to making realistic service life predictions is the lack of adequate models of the movement and accumulation of water in concrete.

\section{SUMMARY}

While the mechanisms of the frost damage of concrete are not unequivocally known, it appears that either hydraulic or osmotic forces, or their combination, are involved. In general, hydraulic pressures are thought to damage concrete if it freezes rapidly or if it is highly porous. If the concrete freezes slowly, then the osmotic force mechanism is thought to dominate.

The resistance of concrete to frost damage is largely controlled by the in-service conditions, the amount and spacing of entrained air in the hardened cement paste, the water-to-cement ratio of the concrete, salts in the concrete pore water, the aggregate frost resistance, and the strength of the concrete. of these factors, the air void structure is the most important. However, even air entrained concrete can undergo frost damage if the concrete is critically saturated when exposed to freezing temperatures (8).

Several distinctly different test methods are available for evaluating the freeze thaw resistance of concrete. The test which is used most often is ASTM C 666 (17). It involves short cycles of freezing and thawing of saturated concrete specimens and measuring the resonance sonic frequency to monitor degradation. This test has been criticized because the test conditions do not simulate normal in-service freezing conditions. However, it is useful as concretes passing the tests have acceptable in-service frost resistance. ASTM C 671 (18) is a dilation test which more closely simulates actual in-service conditions. Several factors have impeded its use, including that it usually requires more time to perform than C 666, and the results obtained with C 671 are sensitive to the moisture content of the concrete prior to testing. However, it has been suggested that $c 671$ is a more realistic test for high-strength concrete than C 666 (15). A critical saturation test (21) has been developed based on the work by Fagerlund ( 8 , 22). In this test, absorption tests are carried out to indicate the approximate time required for concrete to reach the critical degree of saturation. The frost resistance at a given time is the difference between the critical saturation and the actual level of saturation at that time.

Several models have been developed to predict the performance of concrete. The models by Fagerlund $(8,22)$, Vesikari (23), and Bryant and Miakar (25) are aimed at predicting the service life of concrete. The model by olsen (24), while not intended for making service life predictions, with suitable modifications also could be used in making predictions. The model by Bazant, et. al., (26) provides a means to predict the effect of mechanical loading on the 
frost resistance of a concrete structure. These models, with further development, appear to form a promising technical basis for making service life predictions of concrete subjected to frost conditions. A major obstacle to making realistic service life predictions, however, is the lack of adequate models of the movement and accumulation of water in concrete.

\section{REFERENCES}

1. "Concrete Durability, A Multibillion-Dollar Opportunity," National Materials Advisory Board, Report NMAB-361, National Research Council (Washington, D.C., 1981)

2. A.M. Neville, "Properties of Concrete," (3rd ed.), Pitman Publishing Ltd. (London, 1981)。

3. W.A. Cordon, "Freezing and Thawing of Concrete--Mechanisms and Contro1," ACI Monograph No. 3, American Concrete Institute (1966).

4. T.C. Powers, "A Working Hypothesis for Further Studies of Frost Resistance of Concrete," ACI Journal Proceedings, Vol. 41 (4), 245-272 (1945).

5. T.C. Powers, "Basic Considerations Relating to Freezing and Thawing Tests," Proceedings ASTM, Vol. 55, 1132-1155 (1955).

6. T.C. Powers, "Resistance of Concrete to Frost at Early Ages," Proceedings, RILEM Symposium on Winter Concreting (Copenhagen, 1956), Research Bulletin No. 71, Portland Cement Association.

7. R.A. Helmuth, "Capillary Size Restrictions on Ice Formation in Hardened Portland Cement Pastes," 4th International symposium on Chemistry of Cement, Vol. 2, 855-869 (published as Monograph 43, National Bureau of Standards, 1962).

8. G. Fagerlund, "Prediction of the Service Life of Concrete Exposed to Frost Action," in Studies on Concrete Technology, Swedish Cement and Concrete Research Institute (1978).

9. G.G. Litvan "Phase Transitions of Adsorbates: IV. Mechanism of Frost Action in Hardened Cement Paste," Journal of the American Ceramic Society, Vol. 55 (1), 38-42 (1972).

10. R.A. Helmuth, "Dimensional Changes of Hardened Cement Pastes Caused by Temperature Changes," Proceedings Highway Research Board, Vol. 40, 315-336 (1961).

11. G. Verbeck and R. Landgren, "Influence of Physical Characteristics of Aggregates on the Frost Resistance of Concrete," Proceedings ASTM, Vol. 60, 1063-1079 (1960). 
12. "Guide to Durable Concrete," ACI 201.2R-77, American Concrete Institute (1977).

13. T.C. Powers, "The Air Resistance Requirements of FrostResistance Concrete," Highway Research Board, Vol 29 , pp. 184202 (1949.

14. V.M. Malhotra, "Mechanical Properties, and Freezing-andThawing Resistance of Non-Air-Entrained Condensed Silica-Fume concrete using ASTM C 666, Procedures A and B," in Fly Ash, Silica Fume, Slag, and Natural Pozzolans in Concrete, ACI SP91, pp. 1069-1094, American Concrete Institute (1986).

15. R.E. Philleo, "Freezing and Thawing Resistance of HighStrength Concrete," National Cooperative Highway Research Program Synthesis of Highway Practice 129 (1986).

16. R.E. Philleo and J.R. Clifton, "Pore Structure of concrete and Freezing Vulnerability," National Institute of Standards and Technology, NISTIR 89-4186 (1989).

17. "Standard Test Method for Resistance of Concrete to Rapid Freezing and Thawing," ASTM Designation C 666.

18. "Standard Test Method for Critical Dilation of Concrete specimens Subjected to Freezing," ASTM Designation C 671 .

19. R.J. Detwiler, B.J. Dalgleish, and R.B. Williamson,

"Assessing the Durability of Concrete in Freezing and Thawing," ACI Materials Journal, Vol. 86, 29-35 (1988)

20. "Standard Recommended Practice for Evaluation of Frost Resistance of Coarse Aggregates in Air-Entrained concrete by Critical Dilation Procedures," ASTM Designation C 682.

21. G. Fagerlund, "The Critical Degree of Saturation Method of Assessing the Freeze/Thaw Resistance of Concrete," Materials and Structures, Vol 10, 217-229 (1977).

22. G. Fagerlund, "Service Life of Concrete Structure," Proceedings of Contemporary European Concrete Research, Stockholm (1981).

23. E. Vesikari, "Service Life Design of Concrete Structures with Regard to the Frost Resistance of Concrete," Nordic Concrete Research, Publication No. 5, 215-228, Norske Betongforening, (Oslo, 1986).

24. M.P.J. Olsen, "Mathematical Modeling of the Freezing Process of concrete and Aggregates," Cement and concrete Research, Vol. 14, 113-122 (1984). 
25. L.M. Bryant and Paul F. Mlaker, "Estimation of Concrete Service Life," U.S. Army Corps of Engineers Report No. J650-89-002-1420 (Waterways Experimental Station, Vicksburg, MS, 1989).

26. Z.P. Bazant, J.C. Chern, A.M. Rosenberg, and J.M. Gaidis, "Mathematical Model for Freeze-Thaw Durability of Concrete," Report No. 86-11/694m, Center for Concrete and Geomaterials, The Technological Institute, Northwestern Univ. (1962). 
Table 1. Recommended Air Contents for Frost-Resistant Concrete

\begin{tabular}{|c|c|c|c|}
\hline \multirow{2}{*}{\multicolumn{2}{|c|}{$\begin{array}{l}\text { Nominal Maximum } \\
\text { aggregate size } \\
\text { mm (in.) }\end{array}$}} & \multicolumn{2}{|c|}{ Average air content percent ${ }^{a}$} \\
\hline & & $\begin{array}{l}\text { Severe } \\
\text { Exposure }\end{array}$ & $\begin{array}{l}\text { Moderate } \\
\text { Exposure }\end{array}$ \\
\hline 9.5 & $(3 / 8)$ & 7.5 & 6 \\
\hline 12.5 & $(1 / 2)$ & 7 & 5.5 \\
\hline 19 & $(3 / 4)$ & 6 & 5 \\
\hline 38 & $(1.5)$ & 5.5 & 4.5 \\
\hline 75 & (3) & 4.5 & 3.5 \\
\hline 150 & (6) & 4 & 3 \\
\hline
\end{tabular}

a A reasonable tolerance for air content in a field construction is $1-1 / 2$ percent.

b Outdoor exposure in a cold climate where the concrete may be in almost continuous contact with moisture prior to freezing, or where deicing salts are used.

c Outdoor exposure in a cold climate where the concrete will be only occasionally exposed to moisture prior to freezing, and where no deicing salts will be used. 
NIST-114A

(REV. 3-89)
U.S. DEPARTMENT OF COMMERCE NATIONAL INSTITUTE OF STANDARDS AND TECHNOLOGY

\section{BIBLIOGRAPHIC DATA SHEET}

4. TITLE AND SUBTITLE

THE FROST-RESISTANCE OF CONCRETE

5. AUTHOA(S)

James R. Clifton

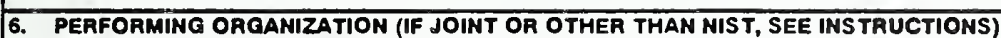

U.S. DEPARTMENT OF COMMERCE

NATIONAL INSTITUTE OF STANDARDS AND TECHNOLOGY

GAITHERSBURG, MD 20899

7. CONTRACT/GRANT NUMBER

8. TYPE OF REPORT AND PERIOD COVERED

9. SPONSORIMO ORGANIZATION NAME AND COMPLETE ADDRESS (STREET, CITY, STATE, ZIP)

10. SUPPLEMENTAAY NOTES

DOCUMENT DESCRIBES A COMPUTEA PROGRAM; SF-185, FIPS SOFTWARE SUMMARY, IS ATTACHED.

11. ABSTRACT (A 20O-WORD OR LESS FACTUAL SUMMARY OF MOST SIGNIFICANT INFOAMATION. IF DOCUMENT INCLUDES A SIGNIFICANT BIBLIOGRAPHY OR LTERATURE SURVEY, MENTION IT HERE.)

Freezing of water in the pores of concrete is one of the major degradation processes of concrete. It results in cracking and reduced service life. Concrete exposed to frost conditions may rapidly degrade or be durable for decades. This report reviews the major factors affecting the frost resistance of concrete and test methods for evaluating the service life of concrete. Mathematical models which describe the mechanisms of frost damage and methodologies for predicting the durability of concrete exposed to frost conditions are reviewed to determine their relevance to service life predictions.

12. KEY WORDS (6 TO 12 ENTRIES; ALPHABETICAL ORDER; CAPITALIZE ONLY PROPER NAMES; AND SEPARATE KEY WORDS BY SEMICOLONS)

aggregate; concrete; durability; entrained-air; freezing; frost; models; service life; testing.

\section{AVAILABIUTYY}

UNUMITED

FOR OFFICIAL DISTRIBUTION. DO NOT RELEASE TO NATIONAL TECHMICAL INFORMATION SERVICE (NTIS).

ORDER FROM SUPERINTENDENT OF DOCUMENTS, U.S. GOVERNMENT PRINTING OFFICE, WASHINGTON, DC 20402.

ORDER FROM NATIONAL TECHNICAL INFORMATION SERVICE (NTIS), SPRINGFIELD, VA 22161.

14. NUMBER OF PRINTED PAGES

21

15. PRICE

$\mathrm{AO} 2$ 

